\title{
Evaluation of Students Utilisation/Implementation of Time Management Skills in University for Development Studies: The Case of Nyankpala Campus
}

\author{
Amos Asamari Alale (PhD) \\ Guidance and Counselling Unit, University for Development Studies, Tamale \\ Juliana Darlebnim Dinko \\ Special Education Unit, St. Joseph's College of Education, P. O. Box 15 Bechem, Ghana \\ Selina Amponsah \\ Department of Family and Consumer Sciences, University for Development Studies, Nyankpala
}

\begin{abstract}
The study was conducted in Nyankpala Campus of the University for Development Studies. The study examined the implementation/utilization of prioritization, planning and avoidance of procrastination as time management skills. The study used the descriptive survey. Proportional and simple random sampling techniques were used to select two hundred and twenty (220) level hundred students from a total of 476. Questionnaire was used to collect data from the respondents using a 5 point Likert-type scale ranging from 5 (strongly agree, SD), 4 (agree, A), 3 (not sure, NS), 2 (disagree, D) to 1 (strongly disagree, SD). The data were collected and analyzed using frequencies, percentages, means and standard deviations with the help of SPSS. A criterion score of 3.50 was used to compare with the mean of means to determine whether a time management skill was effectively utilized/ implemented or not by the students. The study revealed that prioritization and planning as time management skills were effectively implemented /utilized while avoidance of procrastination was poorly or not effectively implemented /utilized. It is recommended that counsellors and lecturers should educate and sensitize students through seminars on how to properly address the issues of procrastination that might negatively affect students' academic performance.

Keywords: Time Management Skills, Academic Performance, University for Development Studies, Tolon District, Nyankpala.
\end{abstract}

DOI: $10.7176 /$ RHSS/10-4-02

Publication date: February $29^{\text {th }} 2020$

\section{Introduction}

Time is indefinite continued progress of existence and events that occur in apparently irreversible succession from the past through the current to the long run (Oxford University Press, 2011). Time is deemed very substantial to human beings. Time is the only exceptional and scarcest resource that is available to everyone in the same amount. To manage time is another sense of distributing priorities and exerting efforts upon that distribution.

According to Karim and Mitra, (2015), time management is the set of principles, practices, skills, tools and systems that work together to help students get more value out of time with the aim of improving the quality of academic standards Also, Campell and Svenson (1992) define time management as the ways students manage their time in order to have better academic performance and success. Time management requires students to abreast themselves with time management strategies such as giving priority to vital matters, focusing on key issues essential for success among others. Poor time management skills such as improper allocation of time or last minute preparation for examinations could lead to poor academic performance. Affirming this assertion, Kaushar (2013) reveals that time management skills play vital roles in students' academic performance. He concluded that lack of time management skills act as barrier to better academic performance. It therefore means that time management skills such as prioritization, planning and avoidance of procrastination among others are essential in helping students obtain best results.

Prioritization is a practice of making a to-do list by writing or typing out what need to be done i.e. physically prioritizing the tasks that are most urgent and important. Prioritizing daily tasks is key to successful time management. When you prioritize, you make sure you accomplish the most important tasks first. According to Johann Wolfgang Von Goethe, (2018) the biggest problem students' face with prioritization is that of late start. He reinforced that things, which matter most, must not be at the mercy of things, which matter least. Also planning is one of the essential time management skills because it allows students specific time required to complete a task. A well-planned time saves a great deal of time. The key to successful time management is planning and then protecting the planned time. People who say that they have no time do not plan, or fail to protect planned time. If you plan what to do and when, and then stick to it, then you will have time.

With regards to procrastination, it is the practice of carrying out less urgent tasks in preference to more urgent 
ones, or doing more pleasurable things in place of less pleasurable ones, and thus putting off impending tasks to a later time. Procrastination may result from not managing time wisely. Being unclear about your priorities, goals, and objectives can result in putting off academic assignments to hang out with friends or perform other activities. What is considered procrastination must be counterproductive, needless, and delaying. Similarly, it is to voluntarily delay an intended course of action despite expecting to be worse off for the delay. Students who procrastinate may experience higher level of frustrations, guilt, stress, and in some cases lead to low self-esteem and depression.

Generally, time management is focused on solving problem of distractions, deadline pressure, procrastination and self-discipline. Individually, the perception of time management varies as Akomolafe (2005) stated that time is not manageable because it cannot be slowed down, sped up or manufactured. However, Quek (2001) believed that time needs to be managed in order to solve the problem of procrastination.

Various researchers have indicated that time management is clearly associated with educational performance (Lahmers \& Zulauf, 2000, Adamson, 2004, Liu, MacCann \& Roberts 2009). Time management skills, of planning and prioritization were positively related to students' academic grades (Liu, MacCann, \& Roberts, 2009). Further, researchers have speculated that time management techniques are essential aspects of self-regulated learning that can lead to higher academic achievement (Dembo \& Eaton, 1997 and Eilam \& Aharon, 2003). Interventions that improve time management will be of value to students if the ability to manage one's time is positively related to academic performance. Despite its importance, it is never an easy task for anybody to manage time effectively and which students of University for Development Studies is not an exception.

University students have less or no parental or teacher control which make it difficult for them to manage their time effectively. Social networks such as whatsApp, twitter, Facebook, Instagram have become popular among students. Students on Nyankpala campus spend time on social events like religious activities, pool party, clubbing, red carpet party, among others. There have been dismissal and repetition of students due to poor academic performance. It appears no research has been done regarding time management. One cannot tell whether students effectively implement or utilize their time on campus or not. It is against this background that this study is deemed necessary. Specifically, the study seeks to examine the extent to which prioritization, planning and procrastination as time management skills are effectively implemented/utilized by students of the Nyankpala Campus of the University for Development Studies.

\section{Research Questions}

Three research questions guided the study.

1. To what extent is prioritization as a time management skill effectively implemented/utilized by students in the Nyankpala Campus of the University?

2. To what extent is time planning as a time management skill effectively implemented/utilized?

3. To what extent is avoidance of procrastination as a time management skill effectively implemented/ utilized?

\section{Methodology \\ Study Area}

The study was carried out in the Nyankpala Campus of University for Development Studies. The University was established in May 1992 under PNDC law 279. Its main mission statement is to promote equitable and socioeconomic transformation of communities through practically oriented, community based, problem solving, gender sensitive and interactive research, teaching, learning and outreach activities. Nyankpala Campus is the premier campus of the four Campuses of the University. Starting with a student population of forty (40) on the Nyankpala Campus in 1993, the Campus as at the 2019/2020 academic year has a total student population of about 2900.

The Nyankpala Campus is in the Tolon District, about $20 \mathrm{~km}$ south -west of Tamale, the capital of the Northern Region of Ghana. ). It coordinates $9^{0} 24^{\prime} 24^{\prime} N 0^{0} 59^{\prime}$ w (Ghana Statistical Service, 2010). The Nyankpala Campus of the University has three Faculties and a School. See Table 1. The study focused on first year students (level 100) of the 2017/2018 academic year group of students. This category of students were preferred to level 200,300 and 400 in the sense that they are new entrants and as a result needs time management skills to pursue their tertiary education. Since first years are new entrants on campus, time management skills will be of value to them.

\section{Research Design}

A descriptive research design was adopted for the study. Descriptive research involves gathering data that describe events and then organizes, tabulates and describes the data collected. It often uses visual aids such as tables and charts to aid the reader in understanding the data distribution. The choice of the design was informed by the fact that it permitted the researcher to describe the way students utilized or implemented prioritization, planning and avoidance of procrastination as time management skills in the pursuit of their academic studies in the university. According to Ary, Jacobs and Razavieh (1990), descriptive design enables researchers to investigate events or 
things that exist at a time the research is conducted.

\section{Population and Sample Size}

The population of the study was made of all level hundred students in the University for Development Studies (UDS) Nyankpala Campus. The total population for level hundred students for the 2017/2018 academic was four hundred and seventy-six (476) while the entire population of the Nyankpala Campus was about1384. Proportional and simple random sampling techniques were used to select two hundred and twenty (220) students out of the population of four hundred and seventy-six (476). See Table 1.

Table 1: Population and Sample Size of Students

\begin{tabular}{llc}
\hline Faculties/School & Population & Sample Size \\
\hline Agriculture & 262 & 121 \\
Agribusiness and Communication & 124 & 57 \\
Renewable Natural Resources & 50 & 24 \\
School of Engineering & 40 & 18 \\
\hline Total & $\mathbf{4 7 6}$ & $\mathbf{2 2 0}$ \\
\hline
\end{tabular}

\section{Research Instrument}

The research instrument for the study was questionnaire. The questionnaire was in two sections, the Bio- data of the respondents and the main body of the questions. The main body was made up of five items for prioritization, seven items for planning and six items for procrastination. The items on each time management skill were structured along a 5 point Likert-type scale ranging from 5 (strongly agree, SD), 4 (agree, A), 3 (not sure, NS), 2 (disagree, D) to 1 ( strongly disagree, SD). The questionnaire was used to gather information from the respondents.. Experts in Measurement and Evaluation and Guidance and Counselling in the Faculty of Education, University for Development Studies helped perfected the questionnaire. They critically scrutinized the questionnaire and offered suggestions. Their suggestions were incorporated to ensure that participants in the main study experience fewer difficulties in completing the items. Means and standard deviations were used to analyse the research questions.

\section{Methods of Data Collection}

Data collection is a technique used to gather empirical research data. The questionnaire was self-administering to the students. Two hundred and twenty (220) questionnaires were administered and were successfully completed and returned.

\section{Data Analysis Procedures}

Analysis and interpretation are required to bring order and understanding to data gathered. Data collected was coded and analyzed using frequencies, percentages, means and standard deviations with the help of Statistical Package for Social Science (SPSS_V20). The criterion used to determine the effectiveness or otherwise of a time management skill was that a mean of mean score of 3.50 or higher shows a time management skill was effectively implemented or utilized while a score less than 3.50 means that a time management skill was not effectively implemented or utilized.

\section{Analyses of Bio-data}

Table 2: Sex of Respondents

\begin{tabular}{lcc}
\hline Sex & Frequency & Percentage \\
\hline Male & 136 & 61.8 \\
Female & 84 & 38.2 \\
\hline Total & $\mathbf{2 2 0}$ & $\mathbf{1 0 0}$ \\
\hline
\end{tabular}

Table 2 reveals that 136 respondents $(61.8 \%)$ were males while 84 respondents $(38.2 \%)$ were females. This might be that more males are admitted into the Nyankpala Campus of the University than females. This difference could be due to the fact that majority of the programmes in the campus are agriculture related. Corroborating this assertion, Akyina, Oduro- Okyireh and Ansah-Hughes (2015) concluded that few females enroll in agriculture science programmes at tertiary level in Ghana. For instance of the 338 students admitted in 2013/2014 academic year to pursue agriculture education at the College of Agriculture Education, University of Education, Winneba only 37 were females. Also in all the levels, they were only 79 females out of a total of 1001 who pursued agriculture science programme in the 2013/2014 academic year.

\section{Results and Discussion}

Research Question 1: To what extent is prioritization as a time management skill effectively utilized? This 
research question sought to find out whether students effectively utilized or implemented prioritization skill. The results are shown in Table 3.

Table 3: Implementation of Prioritization as a Time Management Skill

\begin{tabular}{|c|c|c|c|c|c|c|c|c|}
\hline Statement & SD & D & NS & $\mathbf{A}$ & $\mathbf{S A}$ & Total & Mean & $\begin{array}{l}\text { Standard } \\
\text { Deviation }\end{array}$ \\
\hline $\begin{array}{l}\text { I always work out strategies for } \\
\text { carrying out my daily activities }\end{array}$ & 4 & 14 & 24 & 142 & 36 & 220 & 3.87 & .825 \\
\hline $\begin{array}{l}\text { I write task to be performed in order of } \\
\text { priority }\end{array}$ & 4 & 30 & 54 & 100 & 32 & 220 & 3.57 & .962 \\
\hline I perform task in order of priority & 6 & 36 & 42 & 86 & 50 & 220 & 3.64 & .926 \\
\hline $\begin{array}{l}\text { I assess the accomplishment of } \\
\text { priorities daily }\end{array}$ & 2 & 30 & 46 & 110 & 32 & 220 & 3.63 & 1.09 \\
\hline I allocate time for daily activities & 6 & 46 & 30 & 76 & 56 & 220 & 3.69 & 1.07 \\
\hline & & & & & & & $\begin{array}{l}\text { Mean } \\
\text { Means }= \\
3.68\end{array}$ & $\begin{array}{l}\text { Standard } \\
\text { Deviation } \\
=0.97\end{array}$ \\
\hline
\end{tabular}

\section{Criterion Score 3.50}

Table 3 shows that, the mean of means score for two hundred and twenty (220) respondents is 3.68 with standard deviation of 0.97 . Comparing the mean of means with the criterion score of 3.50 , the mean of mean score is higher which shows that prioritization as a time management skill was effectively implemented or utilized by students. It is evident that prioritization as a time management skill was effectively utilized by students of the Nyankpala Campus of the University for Development Studies. By prioritization, students are in a better position to allocate time for their daily activities and assess the accomplishment of tasks in other of priority. When student prioritize their tasks and responsibilities they achieve their objectives and perform better in their studies. This finding is consistent with the finding obtained by Sevari and Kandy (2011) that prioritization positively affects academic performance of students. Similarly, Adebayo (2015), Karema and Jagalat (2015) found in different studies that prioritization had positive significant relationship on students academics performance.

Research Question 2: To what extent is planning as a time management skill effectively implemented? This research question sought to examine whether students effectively utilize time planning skill. The results are captured in Table 4.

Table 4: Implementation of Planning as a Time Management Skill

\begin{tabular}{|l|l|l|l|l|l|l|l|l|}
\hline $\begin{array}{l}\text { Statement } \\
\text { (Time Planning) }\end{array}$ & SD & D & NS & A & SA & Total & Mean & $\begin{array}{l}\text { Standard } \\
\text { Deviation }\end{array}$ \\
\hline $\begin{array}{l}\text { I plan out revision time table for } \\
\text { exams }\end{array}$ & 8 & 22 & 30 & 98 & 62 & 220 & 3.84 & \\
\hline I have daily routine which I follow & 4 & 28 & 40 & 98 & 62 & 220 & 3.74 & 1.15 \\
\hline $\begin{array}{l}\text { I mark important dates on my } \\
\text { calendar e.g. exams }\end{array}$ & 2 & 34 & 42 & 94 & 48 & 220 & 3.69 & 1.01 \\
\hline $\begin{array}{l}\text { I fixed date to complete my } \\
\text { schedules }\end{array}$ & 2 & 34 & 38 & 98 & 48 & 220 & 3.71 & 1.01 \\
\hline $\begin{array}{l}\text { I revise my lesson notes even if I } \\
\text { don't have exams }\end{array}$ & 6 & 26 & 30 & 104 & 54 & 220 & 3.79 & 1.01 \\
\hline $\begin{array}{l}\text { I plan my day before I start } \\
\text { I determine my priorities }\end{array}$ & 2 & 22 & 38 & 100 & 58 & 220 & 3.86 & 1.03 \\
\hline & & & & & & & $\begin{array}{l}\text { Mean of Means } \\
=3.77\end{array}$ & $\begin{array}{l}\text { Standard } \\
\text { Deviation } \\
=\mathbf{1 . 0 1}\end{array}$ \\
\hline
\end{tabular}

\section{Criterion Score 3.50}

Table 4 shows that, the mean of means score for two hundred and twenty (220) respondents is 3.77 with 
standard deviation of 1.01. The criterion score is 3.50. Since the mean of means core is greater than 3.50 , it means planning as a time management skill was effectively implemented or utilized. This means that majority of the students plan their time effectively and this could improve their academic performance than their counter parts who fail to plan their time effectively. Planning time effectively means students will have daily routine to follow, take notes of important tasks like exams, fix dates for their schedules and revise lesson notes early enough before exams. All these will help students prepare themselves adequately for examination. This could lead to good academic performance. This current finding shares similar views with that of other researches. For example, Kelly (2004) found that time management is one of the keys to higher academic performance. In a similar vein, Nasrulla (2015) reported successful students are good time planners. Also, Agarwal (2008) concluded that students need to be self-disciplined in time planning to improve on their academic performance.

Research Question 3: To what extent is avoidance of procrastination as a time management skill effectively implemented? The purpose of this research question was to find out whether students are able manage procrastination effectively. The results are presented in Table $\mathbf{5}$.

Table 5: Implementation of Procrastination as a Time Management Skill

\begin{tabular}{|l|l|l|l|l|l|l|l|l|}
\hline Statement (Procrastination) & SD & D & NS & A & SA & Total & Mean & $\begin{array}{c}\text { Standard } \\
\text { Deviation }\end{array}$ \\
\hline I see time as always available & 12 & 74 & 32 & 82 & 20 & 220 & 3.11 & 1.14 \\
\hline I post pone duties & 20 & 76 & 38 & 62 & 24 & 220 & 2.93 & 1.20 \\
\hline I am not in a hurry to perform duties & 18 & 62 & 40 & 70 & 30 & 220 & 3.15 & 1.21 \\
\hline I like extension of work & 20 & 76 & 40 & 58 & 26 & 220 & 2.97 & 1.21 \\
\hline $\begin{array}{l}\text { I study my lessons normally few days } \\
\text { before exams }\end{array}$ & 22 & 46 & 30 & 72 & 50 & 220 & 3.37 & 1.31 \\
\hline I love leisure & 10 & 56 & 24 & 72 & 58 & 220 & 3.57 & $\begin{array}{l}\text { Mean } \\
\text { Means= }\end{array}$ \\
\hline
\end{tabular}

\section{Criterion Score 3.50}

Table 5 shows that, the mean of means score for two hundred and (220) respondents is 3.01 with standard deviation of 1.22 while the criterion score is 3.50 . It can be seen that the mean of means score is below 3.50 and this indicates that procrastination was not effectively managed or implemented. Instead, it was poorly managed or utilized. This means majority of the students procrastinate. It is worrisome for students to procrastinate as this could negatively affect their academic performance. Students who procrastinate may experience higher level of frustrations, guilt, stress, low self-esteem and depression. This could lead to poor academic performance and interpersonal relationship. Also, if students see time as always available, they will postpone duties and study lessons. Others may think that, they work better when there is pressure. This could result in inadequate preparation for examination and subsequently lead to high examination anxiety and low academic performance. Confirming this finding, Hen and Goroshit (2012) considered procrastination as an obstacle to academic success. Similarly, McClosky (2011) concluded that procrastination hinders academic achievements of students. However, this finding contradicts the findings of other researches. For instance, Karima, Jagelat and Dalluay (2015) found that procrastination has no impact on academic performance. Also, Davis (2013) found that students still performed better despite frequent procrastination.

\section{Conclusion}

The study revealed that, students effectively implemented or utilized prioritization and time planning skills.

On the contrary, the study showed that procrastination as a time management skill was not effectively implemented or utilized. This is worrisome and problematic as it might affect their academic performance negatively.

\section{Recommendations}

Based on the findings and conclusions drawn, the following recommendations were made for implementation. 
1. Counsellors and Lectures should educate and sensitize students through seminars on how to address the issues of procrastination that might negatively affect student's academic performance.

2. Since students effectively utilize prioritization and time planning, lectures and counsellors should encourage them to continue utilizing such skills to enhance their academic performance.

\section{References}

Adamson, B. J., Covic, T. \& Lincoln, M. (2004). Teaching time and organizational management skills to firstyear health science students: Does training make a difference? Journal of Further and Higher Education, 28, $261-276$

Adebayo, F (2015). Time Management and Students' Academic Performance in Higher Institution, Nigeria: A Case Study of Ekiti State. International Research in Education, 3(2): p. 1-11.

Agarwal, A. (2008). Self-discipline for student-influences on time management. Retrieved August 19, 2012, from http://www.ezinarticles.com.

Akomolafe, C.O. (2005). Principals Time Management abilities in secondary schools in Nigeria. Nigerian Journal of Educational Administration and Planning, 5(1), 58-67.

Akyina, K.O., Oduro- Okyireh, G. \& Ansah-Hughes, W. (2015). Causes of low female choice of agriculture science programme in senior high schools in Afigya Kwabre District: Journal of Educational Policy and Entrepreneurial Research. Vol 2. 7 pg2

Ary, D., Jacobs, L. C., \& Razavieh, A. (1990). Introduction to research in education (4 ${ }^{\text {th }}$ ed.). Forth-Worth, Hol: Rinehart and Winston Inc.

Campbell. R. L., \& Svenson, L.W., (1992). Perceived level of stress among university undergraduate students in Edmonston, Canada. Perceptual and Motor Skills, 75, 552-554

Davis, R. (2013). Social media use may lead to poor grades. Retrieved on 12th/1/2015 from http://www.browndailyherald.com/2013/04/24/social-media-use-may-lead-to-poorgrades/

Dembo, M. H., \& Eaton, M. J. (1997). School learning and motivation. In G. D. Phye (Ed.), Handbook of academic learning: Construction of knowledge (pp. 65-103).San Diego, CA: Academic Press.

Eilam, B., \& Aharon, I. (2003).Students planning in the process of self-regulated learning. Contemporary Educational Psychology, 28, 304-334.

Hen, M. \& Goroshit, M. (2012). Academic Procrastination, Emotional Intelligence, Academic Self-Efficacy and GPA. A comparison between students with disability and without learning disability. Journal of Learning Disability.

Karim, \& Mitra, K. (2015), Time management skills impact on self-efficacy and academic performance. Journal of American Science, 7(12).

Karima Sayari, Revenio Jalagat, Van Dalluay. (2015) Assessing the Relationship of Time Management and Academic Performance of the Business Students in Al-Zahra College for Women. European Business \& Management. Vol. 3, No. 1, 2017, pp. 1-8.doi: 10.11648/j.ebm.20170301.1

Kaushar, M. (2013). Study of Impact of Time Management on Academic Performance of College Students. Journal of Business and Management, 9 (6): p. 59-60.

Kelly, M. (2004). Get time on your side, Careers \& Universities, 24 (4), p. 28.

Lahmers, A.G., \& Zulauf, C. R. (2000). Factors associated with academic time use and academic performance of college students: A recursive approach. Journal of College.

Liu, O. L., Rijmen, F., MacCann, C., \& Roberts, R. (2009). The assessment of time management in middle-school students. Personality and Individual Differences, 47, 174-179.

McClosky, J.D (2011). Academic Procrastination. http:/www.scribal.com/document.

Quek, T. (2001). Procrastination. E.O Dexterity software.

Sevari, K., \& Kandy, M. (2011). Time management skills impact on self-efficacy and academic performance. Journal of American Science, 7(12), 720-72.

Wolfgang, J.H.V.G (2018). Time Management and Organisation http:/www.missouristate.edu 